\title{
Growth and Studies of Potassium Dihydrogen Phosphate Crystals Doped With Picric Acid
}

\author{
T.Manju ${ }^{1}$ and P.Selvarajan ${ }^{2}$ \\ ${ }^{1}$ Research Scholar, Manonmaniam Sundaranar University, Tirunelveli, Tamil Nadu, India \\ ${ }^{2}$ Department of Physics, Aditanar College of Arts and Science, Tiruchendur, Tamil Nadu, India \\ E-Mail: pselvarajanphy@yahoo.co.in
}

\begin{abstract}
Potassium dihydrogen phosphate (KDP) crystal has been doped with picric acid to alter its physical and chemical properties. Picric acid doped KDP salt was synthesized by adding 2 mole\% of picric acid into the aqueous solution of KDP. Using the synthesized salt of picric acid doped KDP and double distilled water, single crystals were grown by solution method with slow evaporation technique. The grown single crystal was subjected to XRD method to find the crystal structure. The functional groups of the sample were found by FTIR method. The elements in the picric acid doped KDP crystal were identified by EDAX and CHN analyses. SHG studies of the sample were done to check the second order NLO property. Dielectric studies for picric acid doped KDP crystal were carried out using a multi-frequency LCR meter. Thermal stability of the sample was found by TG/DTA studies. The microhardness of the sample was also measured at different applied low loads and the results obtained from the various studies are discussed.
\end{abstract}

Keywords: KDP,Doping, Single Crystal, Solution Growth, Characterization, XRD, FTIR, EDAX, NLO, Dielectrics, Thermal Stability, Microhardness

\section{INTRODUCTION}

Potassium dihydrogen phosphate (KDP) crystals possess high optical and structural perfection and it can be used for doubling and tripling of laser radiation frequency. It can be used in harmonic generators, electro-optic switches, modulators, in laser fusion facilities and it is distinguished by high efficiency of nonlinear conversion and a wide optical transparency range which extends upto the short wavelength region of the spectrum. [1,2]. KDP crystal is a negative uniaxial crystal that has a refractive index for extraordinary ray $\left(\mathrm{n}_{\mathrm{e}}\right)$ along the optic axis and refractive index for ordinary ray $\left(n_{0}\right)$ along the other two axes $[3,4]$. It is reported that KDP crystals can absorb a large number of organic substances like dyes, urea, EDTA, ethyl alcohol and these organic substances are incorporated as the dopants [5$10]$.

The study of the kinetics of KDP crystal growth in the presence of some organic molecules shows that the addition of urea to the mother liquor practically does not influence the growth rate for the faces, whereas ethanol and propanol essentially decrease the growth rate of the faces and lead to their tapering. By studying the influence of urea on the optical, nonlinear and other characteristics of KDP crystals, it is showed that urea doped KDP crystals have a higher mechanical strength and thermal stability in comparison with the undoped KDP crystals [11-13]. Picric acid is a highly oxidative, yellow crystalline solid, soluble in water, alcohol, chloroform, most organic solvents, and ether and the presence of three electron withdrawing nitro groups in the picric acid makes it as a good acceptor for neutral carrier donor molecule [14, 15]. Picric acid has been combined with other amino acids to form various complexes and various studies on picrate-type crystals have been reported by many researchers [16-20]. Picric acid is an interesting inorganic matrix modifier due to its large dipole moment and its ability to form an extensive network of hydrogen bonds. The reason for choosing picric acid as the dopant is due to its good optical nonlinearity. Hence, the aim of the work is to grow and study the various properties of KDP crystals doped with picric acid to improve NLO and other properties of KDP crystal

\section{EXPERIMENTAL METHODOLOGY}

\section{A. Synthesis and Crystal Growth}

To synthesize the picric acid doped KDP salt, 2 mole $\%$ of picric acid was added into the aqueous solution of KDP and the solution was stirred well using a hot plate magnetic stirrer. Then the solution was heated at $60^{\circ} \mathrm{C}$ till the salt of picric acid doped KDP was obtained. Re-crystallization was carried out to improve the quality of the salt. Using the synthesized salt of picric acid doped KDP and double distilled water, saturated aqueous solution was prepared and this solution was stirred for 2 hours and filtered using the good quality Whatman filter papers.

The filtered solution was taken a growth vessel covered with a perforated polythene sheet for slow evaporation. To maintain temperature of the solution constant $\left(29^{\circ} \mathrm{C}\right)$, the growth vessel was loaded in a constant temperature bath (accuracy: $\pm 0.01^{\circ} \mathrm{C}$ ). Due to slow evaporation, initially some speck of crystal nuclei are formed after 3 days. Then, the speck of nuclei grew into big-sized crystals as the solvent evaporated from the solution after a growth period of 20 days. The harvested crystals of picric acid doped KDP are kept in a graph sheet and photographed and it is shown in the figure 1 . The grown crystals are found to be slightly yellow coloured, transparent and non-hygroscopic. 


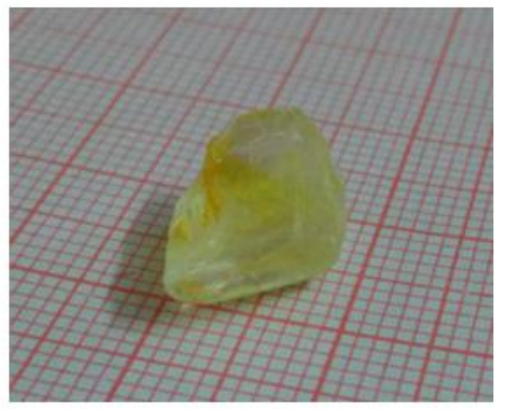

Fig. 1 Harvested Crystal of Picric Acid Doped KDP

\section{B. Measurement of Solubility}

Solubility of a sample in a particular solvent was determined by gravimetrical method at various temperatures in the range $30-50^{\circ} \mathrm{C}$. A constant temperature bath with an accuracy of $\pm 0.01^{\circ} \mathrm{C}$ was used to keep the temperature of the solution constant and an immersible stirrer was used for stirring the solution to achieve the stabilization. After stirring the solution, $10 \mathrm{ml}$ of saturated aqueous solution of was taken in a petri dish and it was warmed to remove the solvent. Then by weighing the petri dish with the deposited solute and empty petri dish separately, the solubility was determined. The variations of solubility of the undoped and picric acid doped KDP with temperature are presented in the figure 2. The results show that the solubility increases with increases of temperature for both the samples and the solubility is observed to be decreased when KDP crystal is doped with picric acid.

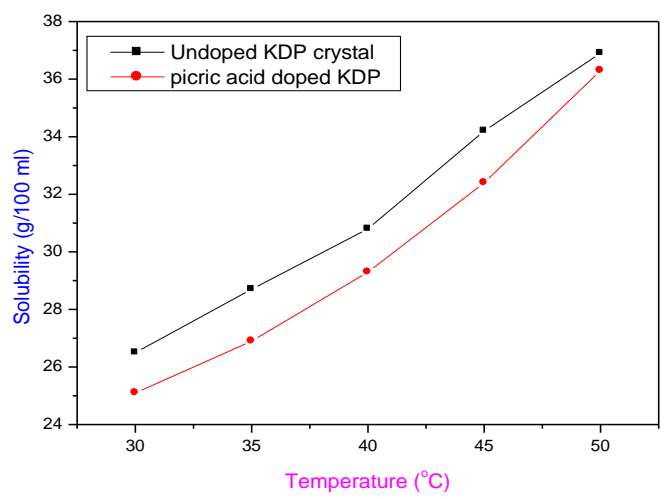

Fig.2 Solubility Curves for Undoped and Picric Acid Doped KDP Crystals

\section{III.RESULTS AND DISCUSSION}

\section{A. FTIR Characterization}

Fourier transform infrared (FTIR) spectroscopy is used to identify the functional groups of the samples. FTIR studies involve the examination of stretching, bending, twisting and rotating vibrational modes of atoms in a molecule and hence to identify the functional groups of samples. The FTIR spectrum of picric acid doped KDP crystal was recorded using a Perkin-Elmer FTIR spectrometer in the wave number range $400-4000 \mathrm{~cm}^{-1}$ using a $\mathrm{KBr}$ pellet technique and it is shown in the figure 3 . The small peaks above 3500 $\mathrm{cm}^{-1}$ are corresponding to the $\mathrm{OH}$ stretching vibrations in the free water molecules and the broad peak at $3439 \mathrm{~cm}^{-1}$ is attributed to $\mathrm{OH}$ stretching mode of the sample. The absorption peaks at 2923 and $2355 \mathrm{~cm}^{-1}$ are due to P-O-H stretching vibration and the strong peak at $1631 \mathrm{~cm}^{-1}$ is corresponding to $\mathrm{O}=\mathrm{P}-\mathrm{OH}$ stretching and $\mathrm{OH}$ bending vibration. The vibration peak at $1080 \mathrm{~cm}^{-1}$ is due to $\mathrm{P}=\mathrm{O}$ stretching vibration. The peak at $544 \mathrm{~cm}^{-1}$ is due to HO-P$\mathrm{OH}$ bending vibration and the peak at $466 \mathrm{~cm}^{-1}$ is due to $\mathrm{PO}_{4}$ stretching vibration. The other vibrational peaks in the spectrum are attributed to the presence of dopant in the host KDP crystal. The assignments to the FTIR vibrational peaks are given in accordance with the data reported in the literature $[21,1]$.

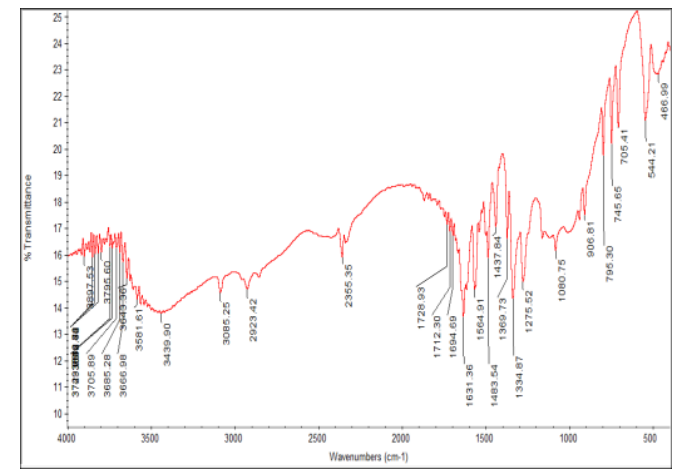

Fig. 3 FTIR Spectrum of Picric Acid Doped KDP Crystal

\section{B. Thermal Studies}

Thermal studies was carried out for picric acid doped KDP crystal by recording the TG/DTA thermal curves in the temperature range $30-800^{\circ} \mathrm{C}$ in the nitrogen atmosphere. The recorded TG/DTA curves for picric acid doped KDP crystal are shown in the figure 4. From TG thermal curve, there is a slight weight loss observed in the temperature range $30-50^{\circ} \mathrm{C}$ and this is due to removal of moisture in the sample. The more moisture is adsorbed with the sample due to doping of picric acid. After that TG shows constant weight of the sample is observed in the temperature range $50-250^{\circ} \mathrm{C}$ and there as a weight loss of about $25 \%$ is noticed in the temperature range $250-470^{\circ} \mathrm{C}$. After that the weight of the sample almost remains constant upto $800^{\circ} \mathrm{C}$.

DTA curves show a broad endothermic peak at $220^{\circ} \mathrm{C}$ and a sharp exothermic peak at $400^{\circ} \mathrm{C}$. The initial decomposition of the sample was started at $220^{\circ} \mathrm{C}$ and ends at $400^{\circ} \mathrm{C}$ and in this decomposition stage, potassium orthophosphate is changed to potassium metaphosphate. The average decomposition point of picric acid doped KDP sample is found to be $300^{\circ} \mathrm{C}$. But the average decomposition point of undoped $\mathrm{KDP}$ crystal is observed to be $277^{\circ} \mathrm{C}$ as reported in the literature [22, 23]. Thus, the thermal stability of picric acid doped KDP crystal is found to be more than that of undoped KDP crystal. The exothermic peak at $400^{\circ} \mathrm{C}$ is indicated by removal of gaseous particles at the 
decomposition of the sample. This increase of thermal stability of the host KDP crystal is due to presence of picric acid in the form of ions in the interstitial positions of the sample.

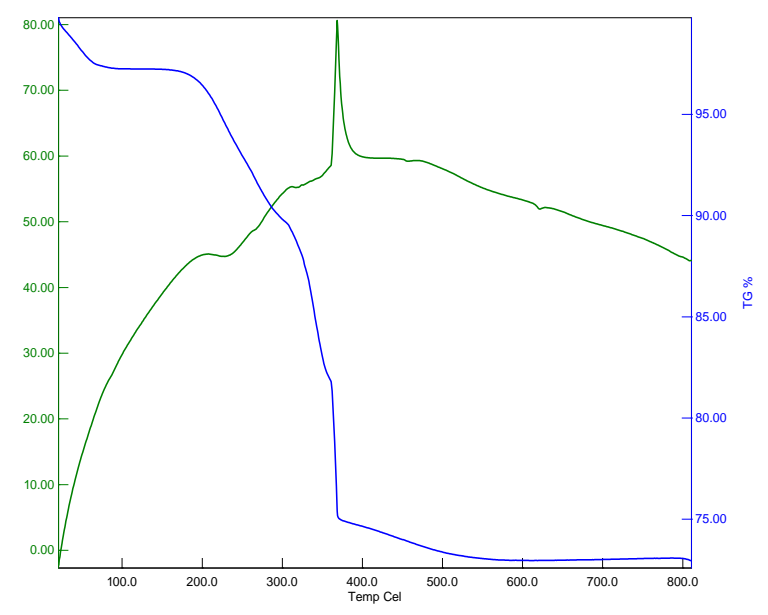

Fig. 4 TG/DTA Thermal Curves for Picric Acid Doped KDP Crystal

\section{Finding Elements in the Sample}

Energy dispersive spectroscopy (EDS) or EDAX is an analytical technique used for the elemental analysis a sample. It relies on the investigation of a sample through interaction between electromagnetic radiation and matter, analyzing X-rays emitted by the matter in response to being hit with charged particles. The EDAX detector measures the relative abundance of emitted X-rays versus their energy. EDAX is combined with an electron microscope and the recorded EDAX spectrum of picric acid doped KDP crystal is shown in the figure 5. The spectrum indicates that the sample has the elements like P, N, C, Oand K. The hydrogen cannot be detected from the sample using EDAX and hence $\mathrm{CHN}$ analysis was carried out to find the weight percentage of hydrogen in the sample. The weight percentage of the elements present in picric acid doped KDP crystal is provided in the Table I.

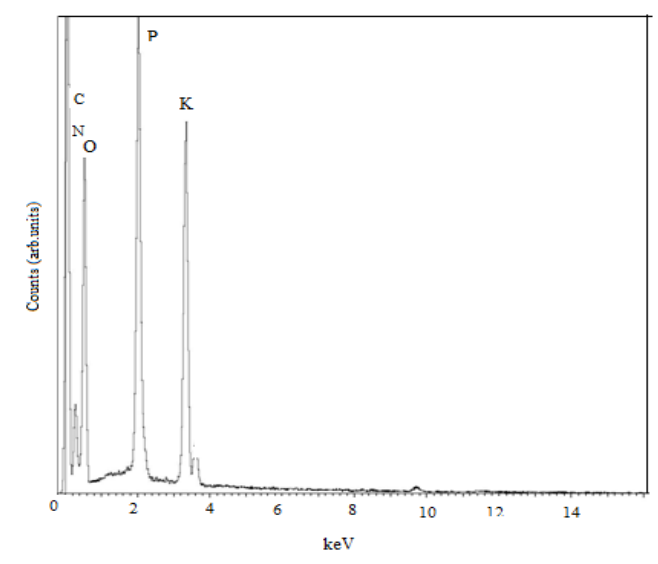

Fig. 5 EDAX Spectrum of Picric Acid Doped KDP Crystal
TABLE I WEIGHT PERCENTAGE OF ELEMENTS IN PICRIC ACID DOPED KDP CRYSTAL

\begin{tabular}{|c|l|c|}
\hline S.No. & Element & Weight $(\boldsymbol{\%})$ \\
\hline 1 & Carbon & 0.583 \\
\hline 2 & Nitrogen & 0.682 \\
\hline 3 & Oxygen & 47.031 \\
\hline 4 & Phosphorus & 22.140 \\
\hline 5 & Potassium & 28.702 \\
\hline 6 & Hydrogen & 1.476 \\
\hline
\end{tabular}

\section{Finding Crystal Structure and Density of Crystal}

$\mathrm{X}$-ray diffraction (XRD) is a rapid analytical technique primarily used for phase identification of a crystalline material and can provide information on unit cell dimensions. For a given set of lattice planes with an interplanar distance of $\mathrm{d}$, the condition for a diffraction to occur can be written as $2 \mathrm{~d} \sin \theta=\mathrm{n} \lambda$ where 1 is the wavelength of $\mathrm{X}$-rays, $\mathrm{n}$ is an integer and $\theta$ is the Bragg's diffraction angle. This condition is used in X-ray diffractometers. Single crystal X-ray diffraction analysis for picric acid doped KDP crystal was carried out using a Bruker Kappa Apex II Xray diffractrometer with $\operatorname{MoK}_{\alpha}$ radiation $(\lambda=0.71069 \AA$ ). The obtained lattice parameters for the sample are $\mathrm{a}=\mathrm{b}=$ 7.504 (6) $\AA \hat{,}, c=6.943(3) \AA \hat{\alpha}, \alpha=90^{\circ}, \beta=90^{\circ}, \gamma=90^{\circ}, \mathrm{V}=$ $390.95(2)(\AA)^{3}$. From the data, it is ascertained that the sample crystallizes in tetragonal structure. The lattice parameters obtained here for the picric acid doped KDP crystal are almost the same as given in the JCPDS card No. 35-0807[23].

Hence, the crystal structure of picric acid doped KDP crystal is found to be the same as the undoped KDP crystal. Since the dopant picric acid is residing in the interstitial position of the host KDP crystal, the crystal structure of the undoped and picric acid doped KDP is observed to be the tetragonal structure. Using XRD data, the density of the grown crystal was determined. The relation used to determine the density of a crystal is $\rho=(\mathrm{M} . \mathrm{Z}) /(\mathrm{N} . \mathrm{V})$ where $\mathrm{M}$ is the molecular weight of the material used, $\mathrm{Z}$ is the number of molecular units per unit cell, $\mathrm{N}$ is Avogadro's number and $\mathrm{V}$ is the volume of the unit cell. It is reported that the unit cell of KDP crystal contains four molecular units $(\mathrm{Z})$ as shown in the diagram 6 . In the unit cell diagram of KDP structure, fundamental $\mathrm{PO}_{4}$ units are bonded together through the $\mathrm{H}$ atoms in the hydroxy groups of the O's of $\mathrm{PO}_{4}$ as reported by West [24].

Using the crystallographic data, the density of picric acid doped KDP crystal was found to be $2.311 \mathrm{~g} / \mathrm{cc}$. Also the floatation method was adopted for the determination of density of crystals. In this method, a high density liquid like bromoform and a low density liquid like carbon tetra chloride or xylene are used. After mixing the liquids in a suitable proportion in a specific gravity bottle, a small piece of a crystal was immersed in the mixture of the liquids. 
When the sample is neither sinks nor floats in the liquids, the density of the crystal would be equal to the density of mixture of liquids. The density was calculated using the relation $\rho=\left(\mathrm{w}_{3}-\mathrm{w}_{2}\right) /\left(\mathrm{w}_{2}-\mathrm{w}_{1}\right)$ where $\mathrm{w}_{1}$ is the weight of the empty specific gravity bottle, $w_{2}$ is the weight of the specific gravity bottle with full of water and $w_{3}$ is the weight of the specific gravity bottle full of the mixture of the solution. By floatation method, the density of picric acid doped KDP crystal was found to be $2.309 \mathrm{~g} / \mathrm{cc}$. It is reported that the density of undoped KDP crystal is $2.345 \mathrm{~g} / \mathrm{cc}$. The slight decrease of density of host KDP crystal due to doping of organic dopant like picric acid is due to slight increase of volume of the unit cell. The picric acid in the form of ions may be in the interstitial positions of lattice of KDP crystal and hence it is possible that the volume of unit cell may be slightly increased [25].

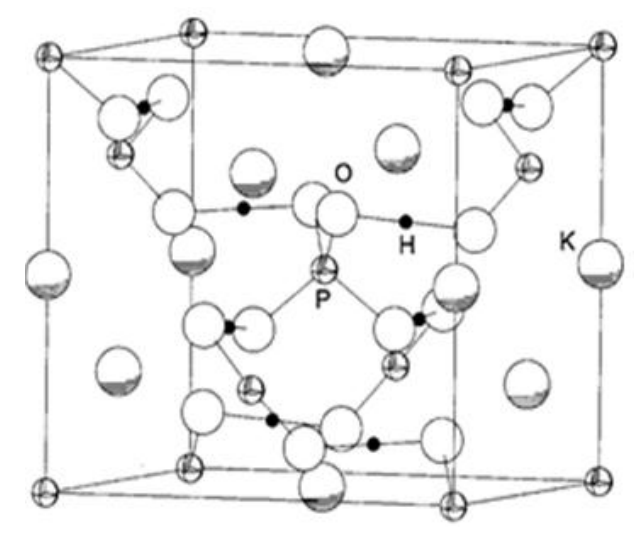

Fig. 6 Unit Cell Diagram of KDP Crystal

\section{E. Hardness Test}

Hardness testing is the simplest and the least expensive method for mechanical characterization of NLO crystals. Hardness testing also provides information regarding other mechanical properties like tensile strength, yield strength and work hardening coefficient. A grown and polished crystal of picric acid doped KDP was selected for microhardness measurement. Microhardness analysis was carried out using Shimadzu Vickers microhardness tester fitted with a diamond indenter attached to an incident light microscope. The well-polished crystal was placed on the platform of the Vickers microhardness tester and the loads of different magnitude were applied over a fixed interval of time. The microhardness number was determined using the relation $\mathrm{H}_{\mathrm{v}}=1.8544 \mathrm{P} / \mathrm{d}^{2}$ where $\mathrm{P}$ is applied load and $\mathrm{d}$ is the average diagonal indentation length [26]. The variation of hardness number with the applied load for the sample is shown in the figure 7 . The results show that hardness number increases as the applied load increases. The increasing trend of the curve is due to the reverse indentation size effect. Initially, when low load is applied the sample is hardened and it can withstand more loads. This is the reason the hardness is more when applied load on the sample is more. Comparing the hardness values of undoped KDP crystal in the literature, the hardness of picric acid KDP crystal is more than that of undoped KDP crystal [27].

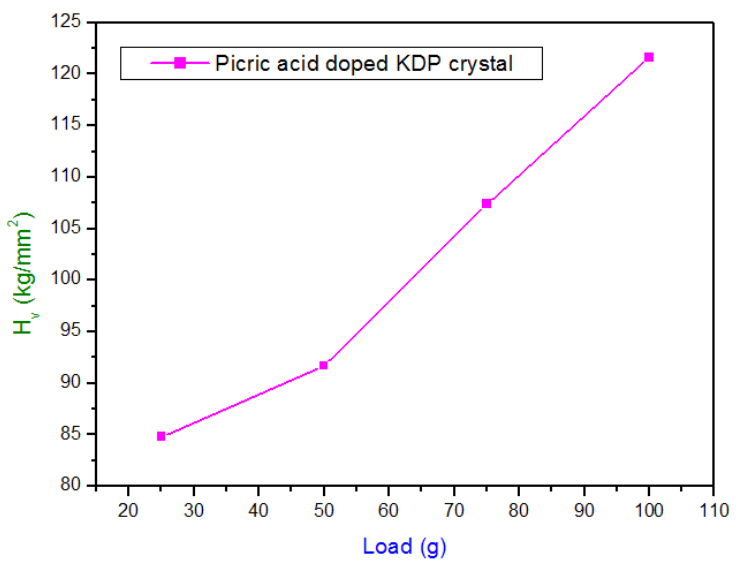

Fig.7 Plot of Hardness Number versus Load for Picric Acid Doped KDP crystal

\section{F. Dielectric Characterization}

Every dielectric material has a unique set of electrical characteristics that are dependent on its dielectric or insulation properties. Accurate measurements of these properties can provide valuable information for a proper manufacturing process. The most commonly measured small signal electrical property is the relative permittivity $\left(\varepsilon_{\mathrm{r}}\right)$ or the dielectric constant. The dielectric constant is defined as the ratio of the capacitance of the material to the capacitance of air. The capacitance of the capacitor without dielectric is given by $C_{0}=\varepsilon_{0} A / d$ where $A$ is the area of the plates of the capacitor, $\varepsilon_{0}$ is the permittivity of free space or vacuum and $d$ is the distance of separation between them. If a dielectric material is inserted between the plates, the charge on the plates increases due to polarization in the material and the capacitance is now given by $\mathrm{C}=\varepsilon_{\mathrm{o}} \varepsilon_{\mathrm{r}} \mathrm{A} / \mathrm{d}$. Using these relations, the dielectric constant $\left(\varepsilon_{\mathrm{r}}\right)$ is calculated. When AC voltage is applied to the dielectric material, the electrical energy is absorbed by the dielectric and certain quantity of electrical energy is dissipated in the form of heat energy [28,29]. This dissipation of electrical energy is known as dielectric loss and it is directly measured using the LCR meter.

In this work, dielectric constant and dielectric loss of the grown crystal of picric acid doped KDP were measured using the Agilent (4284A) precision LCR meter at different frequencies ranging from $10^{2}$ to $10^{6} \mathrm{~Hz}$ and at different temperatures. The plots of frequency dependence of dielectric constant and dielectric loss of picric acid doped KDP crystal at different temperatures are shown in the figures 8 and 9 . The results show that both dielectric constant and loss factor decrease with increase of frequency and these dielectric parameters are observed to be increasing with increase of temperature. At low frequency region $\left(10^{2}-10^{3} \mathrm{~Hz}\right)$, the space charge polarization is predominant and hence dielectric constant is more in the low frequency region. The orientational polarization is observed in the frequency region $\left(10^{3}-10^{5} \mathrm{~Hz}\right)$ and ionic 
polarizationand electronic polarization are noticed in frequencies more than $10^{5} \mathrm{~Hz}$ [30]. The variations of dielectric constant with frequency and temperature indicate the types of polarization present in them. The low value of dielectric loss of picric acid doped KDP crystal indicates that the sample is a good quality dielectric material. Comparing the dielectric parameters of undoped KDP crystal as reported in the literature [23], the dielectric parameters like dielectric constant and dielectric loss of picric acid doped KDP crystal are observed to be more and this variation is due to the organic dopant like picric acid incorporated into the host KDP crystal.

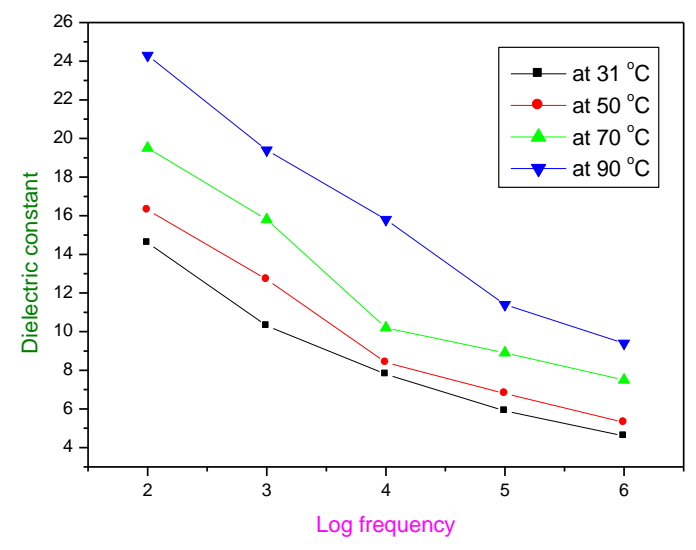

Fig.8 Variation of Dielectric Constant with Frequency for Picric Acid Doped KDP Crystal at Different Temperatures

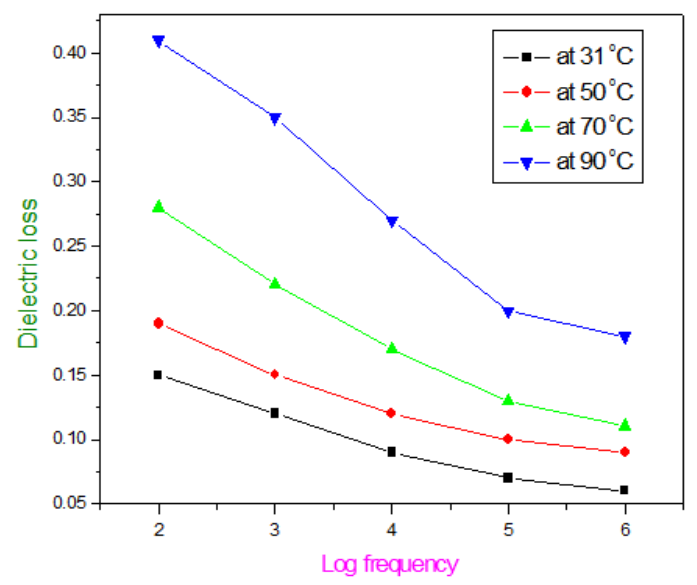

Fig. 9 Variation of Dielectric Loss with Frequency for Picric Acid Doped KDP Crystal at Different Temperatures

\section{G. Second Harmonic Generation}

Second harmonic generation (SHG) is a second NLO phenomenon and it is also called as the frequency doubling. The SHG emission from the sample was checked by KurtzPerry powder technique and here a pulsed Nd:YAG laser with the input wavelength of $1064 \mathrm{~nm}$ was used [31]. The grown crystal was ground to powder of grain size 400-500 $\mu \mathrm{m}$ and subjected to measurement of SHG. From this technique, it is noticed that there is an emission of green radiation with a wavelength of $532 \mathrm{~nm}$ from the sample. The second harmonic generation signal of $11.68 \mathrm{~mJ}$ was observed for picric acid doped KDP crystalline sample for an input energy of $0.70 \mathrm{~J}$. But the standard KDP sample gave an SHG signal of $8.91 \mathrm{~mJ}$ for the same input energy. Hence, relative SHG efficiency of picric acid doped KDP crystal is 1.31 times that of the undoped KDP sample. All the data in connection with SHG studies of the samples are given in the table II. Hence, the picric acid doped KDP crystal is the better candidate for SHG applications.

TABLE II RELEVANT SHG DATA FOR PICRIC ACID DOPED KDP CRYSTAL

\begin{tabular}{|c|l|c|c|c|}
\hline $\begin{array}{c}\text { S. } \\
\text { No. }\end{array}$ & $\begin{array}{l}\text { Sample Code / } \\
\text { Name } \\
\text { of the Sample }\end{array}$ & $\begin{array}{c}\text { Output } \\
\text { Energy } \\
\text { (milli } \\
\text { joule) }\end{array}$ & $\begin{array}{c}\text { Input } \\
\text { Energy } \\
\text { (joule) }\end{array}$ & $\begin{array}{c}\text { Relative } \\
\text { SHG } \\
\text { efficiency }\end{array}$ \\
\hline 1 & $\begin{array}{l}\text { Picric acid } \\
\text { doped KDP }\end{array}$ & 11.68 & 0.70 & 1.31 \\
\hline 2 & $\begin{array}{l}\text { KDP } \\
\text { (Reference) }\end{array}$ & 8.91 & 0.70 & 1 \\
\hline
\end{tabular}

\section{CONCLUSION}

Picric acid doped KDP salt was synthesized and single crystals of the synthesized salt were grown by solution method. It found that the sample has positive temperature coefficient of solubility. The crystal structure of picric acid doped KDP crystal was found to be tetragonal. SHG efficiency of the powdered sample was observed to be 1.31 times that of undoped KDP. The decomposition point of picric acid KDP crystal is noticed to be more than that of undoped KDP crystal. The functional groups of the sample were identified by FTIR analysis. The hardness of the sample is found to be increasing with increase of the applied load. The various elements present in picric acid doped KDP crystal were identified by EDAX and CHN analyses. The density of the sample was found by floatation method and XRD method. Dielectric constant and dielectric loss of the sample were determined at different frequencies and temperatures.

\section{REFERENCES}

[1] I. Pritula, A. Kosinova, M. Kolybayeva, V. Puzikov, S. Bondarenko, V. Tkachenko, V.Tsurikov and O. Fesenko, "Optical, Structural and Microhardness Properties of KDP Crystals Grown from Urea-Doped Solutions", Materials Research Bulletin, Vol. 43, pp. 2778-2789, 2008.

[2] N. Zaitseva and L. Carman, "Rapid Growth of KDP-Type Crystals", Prog. Cryst. Growth Char. Mater., Vol. 43, pp.1-118, 2001.

[3] Masahiro Nakatsuka, Kana Fujioka, Tadashi Kanabe andHisa-nori Fujita,"RapidGrowth Over $50 \mathrm{~mm} /$ day of Water-Soluble KDP Crystal”, J. Crystal Growth, Vol. 171, pp. 531-537, 1997.

[4] Y.N. Velikhov, I.M. Pritula, V.I. Salo and M.I. Kolybaeva, "KDP Crystals -Characterization", Inorg. Mater, Vol.36, pp.734, 2000.

[5] H. Miki, R. Fukunaga, Y. Asakuma, K. Maeda and K. Fukui, "Distribution of Dye into KDP Crystals in a Continuous MSMPR Crystallizer", J. Sep. Purif. Technol., Vol. 43, pp. 77-83, 2005.

[6] Yu. Velikhov, I. Pritula, I. Ganina, M. Kolybayeva, V. Puzikov and A. N. Levchenko, "Growth and Properties of Dye Doped KDP Crystals", Cryst. Res. Technol., Vol. 42, pp.27-33, 2007. 
[7] N.P. Rajesh, V. Kannan, P.SanthanaRaghavan, P. Ramasamy and C.W. Lan, "Optical and Microhardness Studies of KDP Crystals Grown from Aqueous Solutions of Organic Additives", Mater. Lett., Vol. 52, pp.326-328, 2002.

[8] Y. Enqvist, J. Partanen, M. Louhi-Kultanen and J. Kallas, "Thermodynamics and Kinetics of KDP Crystal Growth from Binary and Ternary Solutions", Chem. Eng. Res. Design, Vol. 81, pp. 1354-1362, 2003.

[9] I.V. Shnaidshtein, B.A. Strukov, S.V. Grabovskii, T.V. Pavlovskaya and L. Carman, "Effect of an Organic Dye onthe Ferroelectric Phase Transition in $\mathrm{KH}_{2} \mathrm{PO}_{4}$ (KDP)", Phys. Solid State, Vol. 43, pp. 22762279, 2001.

[10] S.V. Grabovskii, I.V. Shnaidshtein and B.A. Strukov,"Effect of Organic Dyes on Dielectric Properties of KDPCrystals", Phys. Solid State, Vol. 45, pp. 547-552, 2003.

[11] S.V. Grabovskii, I. V. Shnaidshtein and B.A. Strukov, "DielectricProperties of Rapidly Grown KDP Crystals", Crystallography Reports, Vol.48, pp. 322-325, 2003.

[12] J. Podder, "The Study of Impurities Effect on the Growth and Nucleation Kinetics of KDP”, J. Crystal Growth, Vol.237, pp. 70-75, 2002.

[13] S. Hirota, H. Miki, K. Fukui and K. Maeda, "Material Characterization of KDP Crystals", J. Crystal Growth, Vol. 235, pp. 41-545, 2002.

[14] P.G. Farrell, F. Terrier and R. Schaal, "The Effects of Solvation upon the Acidities of Nitroaromatics", Tetrahedron Lett., Vol.26, pp.24352438,1985 .

[15] T.Dhanabal, G. Amirthaganesan, M. Dhandapani and Samar K Das, "Synthesis, Structure, Thermal and NLO Characterization of 4hydroxy Tetramethylpiperazinium Picrate Crystals",J.Chem. Sci., Vol.124, pp. 951-96, 2012.

[16] T. Uma Devi, N. Lawrence, R. Ramesh Babu and K. Ramamurthi,"Growth and characterization of Glycine Picrate Single Crystal",J.Crystal Growth, Vol. 310, pp. 116-123,2008.

[17] Mohd.Shkir, B. Riscob and G. Bhagavannarayana, "Synthesis, Growth, Structural, Spectroscopic, Crystalline Perfection, Second Harmonic Generation and Thermal Studies of 2-Aminopyridinium Picrate: A New Nonlinear Optical Material", Solid State Sciences, Vol.14, pp. 773-776, 2012.

[18] S. Anandhi, T. S. Shyju, T.P.Srinivasan andR.Gopalakrishnan, "Investigaitons on Growth and Characterization of Imidazoloium Picrate: An Organic Salt", J.Crystal Growth, Vol.335, pp.75-83, 2011.
[19] M.Fleck, V.V.Ghazaryan and A.M.Petrosyan, " $\beta$-alaninium picrate: A new salt with di- $\square$-alanimiumdimericcation", J. Molecular Structure, Vol. 1019, pp. 91-96, 2012.

[20] D. Shanthi, P. Selvarajan, S. Perumal, Growth, linear optical constants and photoluminescence characteristics of beta-alaninium picrate(BAP) crystals, Optik, Vol. 127, pp. 3192-3199, 2016.

[21] W.L. Liu, H.R. Xia, X.Q. Wang, Z.C. Ling, D.G. Ran, J. Xu, Y.L. Wei, Y.K. Liu, S.Q. Sun and H. Han, "Characterization of Deutrated Potassium Dihydrogen Phosphate Single Crystals Grown by Circulating Method", J. Crystal Growth, Vol. 293, pp. 387-393, 2006.

[22] S. S. Hussaini, N. R. Dhumane, G. Rabbani, P. Karmuse, V. G. Dongre and M. D. Shirsat, "Growth and High Frequency Dielectric Study of Pure and Thiourea Doped KDP Crystals", Cryst. Res. Technol.,Vol. 42, pp. 1110-1116, 2007.

[23] K. Boopathi and P. Ramasamy, "Effect of L-tyrosine on Solubility, Growth, Structural, Optical, SHG, Dielectric and Mechanical Properties of KDP Single Crystals", Opt. Mater., Vol. 37, pp. 629634, 2014.

[24] J. West, "Kristallgeometrie", Kristall Phys. and Kristallchem., Z. Kristallogr., Vol.74, pp.306, 1930.

[25] T. H.Freeda and C.Mahadevan, "Lattice Variation and Themal Parameters of Gel Grown KDP Crystals added with some Ammonium Compounds", Pramana-Journal of Physics, Vol.57, pp. 829-836, 2001.

[26] T.Gurumurthi and P.Murugakoothan, "Synthesis, Growth and Characterization of Nonlinear Optical Ce-doped L-Prolinium Picrate Single Crystals", Asian J. Chem., Vol.26, pp. 5003-5007, 2014.

[27] T. Manju and P. Selvarajan, "Nucleation Kinetics, Metastable Zone Width and Characterization of Ferric Sulfate Doped KDP Crystals Grown by Slow Evaporation Technique", Int. J. Curr. Res. Modern Edu., Vol. 3, pp. 523-533, 2018.

[28]C.Burfoot Jack and W. George Taylor, " Polar Dielectric and their Applications", The MacmillanPress, London, pp.157-178,1979.

[29] B.Tareev, "Physics of Dielectric Materials", Mir Publishers, Moscow, pp.76-135,1979.

[30] B.Want, F. Ahmad and P.N. Kotru, "Dielectric and Thermal Behavior of Holminum Tartrate Trihydrate Crystals", Cryst. Res. Technol., Vol. 42, pp. $822-828,2007$.

[31] S. K. Kurtz and T.T. Perry, "A Powder Technique for the Evaluation of Nonlinear Optical Materials", J. Appl. Phys., Vol. 39, pp. 3798$3813,1968$. 